\title{
LOCALIZATION OF HUMANIN IN HUMAN, RABBIT AND MOUSE SPERM
}

\section{Geminiani M, Moretti E, Giannerini V, Rossini L ${ }^{1}$, Cardinali R ${ }^{2}$, Trabalzini L ${ }^{3}$, Renieri T, Collodel G}

\author{
Department of Biomedical Sciences, Applied Biology Section, \\ Interdepartmental Centre for Research and Therapy of Male Infertility; \\ 'Siena Biotech; \\ ${ }^{2}$ Department of Applied Biology, Animal Science Section, University of Perugia; \\ ${ }^{3}$ Department of Molecular Biology, University of Siena.
}

\begin{abstract}
Objective: Humanin (HN) is a peptide showing neuroprotective properties against damage associated with Alzheimer's disease. In male reproductive system HN is expressed in human and rat testis. This preliminary study aimed to localize HN by immunocytochemistry (ICC) directly in human, mouse and rabbit sperm. Material and Methods: Semen samples were processed for the ICC analyses using two different rabbit polyclonal anti-HN antibodies. Western blotting analyses were performed using fresh human semen samples. Results: Normal human, rabbit and mouse sperm, showed HN labeling in sub-acrosomal and mid-piece regions, whereas human abnormally shaped sperm were stained also at acrosomal level and particularly in the flagellum. Western blotting analysis revealed the presence of $\mathrm{HN}$ in analyzed human semen samples. Discussion: HN was localized directly on human, rabbit and mouse spermatozoa. In human samples, we demonstrated a different localization pattern in normally shaped sperm compared to abnormal sperm probably due to a protective effect of HN in pathological sperm.
\end{abstract}

Key words: Humanin, immunocytochemistry, immunoelectronmicroscopy, sperm.

\section{INTRODUCTION}

Humanin (HN) is a 24-amino acid peptide showing potent neuroprotective properties against damage associated with Alzheimer's disease (1). In neuronal cells, HN acts by inhibiting apoptosis via multiple mechanisms: it can suppress mitochondrially-mediated apoptosis by interfering with Bax activation (2), additionally it can bind to the Insulin Growth FactorBinding Protein 3 (IGFBP-3) antagonizing its apoptotic actions (3). Ying et al. (4) demonstrated that HN inhibited beta-amyloid $(A \beta)$ 42-induced neurotoxicity by binding to G-protein-coupled receptor FPRL-1. Moreover, neuronal protection by HN involves activation of tyrosine kinases, STAT-3 phosphorylation (5) and the binding to a complex or complexes involving CNTFR/WSX-1/gp180 (6).

The homologues of HN in the rat is called Rattin (HNr) (7) and share, like HN, neuroprotective properties. HN and $\mathrm{HNr}$ have a broader spectrum of protective activity also in non-neuronal cells. Regarding the male reproductive system, studies reported the presence of HN both in human and rat, proposing that this peptide may play a role as a testicular anti-apoptotic factor (8-10). This study aimed to investigate the presence and to localize HN, mainly by immunocytochemistry (ICC), directly in human, mouse and rabbit sperm.

\section{MATERIAl AND Methods}

\section{Immunocytochemistry (ICC)}

Human semen samples were evaluated following World Health Organization guidelines (11) and processed for the ICC analyses. Ejaculated spermatozoa, washed in phosphate-buffered saline (PBS), were smeared on glass slides, air dried, rinsed in PBS and saturated for 20 min with PBS-bovine serum albumin (BSA) $1 \%$ containing $5 \%$ normal goat serum (NGS). The specimens were then incubated overnight at $4^{\circ} \mathrm{C}$ using two different rabbit polyclonal anti-HN antibodies (Sigma-Aldrich, USA and a self made antibody P04, kindly gift of Prof. Matzuoka) both diluted 1:50 in PBS $/ 0.1 \%$ BSA/1\% NGS. For the detection a goat antirabbit FITC conjugate antibody (Sigma-Aldrich), diluted 1:300, was used. The same ICC analysis was carried out also in sperm from rabbit and mouse. The fluorescence was observed with a Leitz Aristoplan light microscope equipped with fluorescence apparatus. Incubation in primary antibodies was omitted in control samples.

\section{Test for antibody specificity}

Preadsorption: An aliquot of rabbit polyclonal anti-HN antibody (Sigma-Aldrich) was pre-incubated 

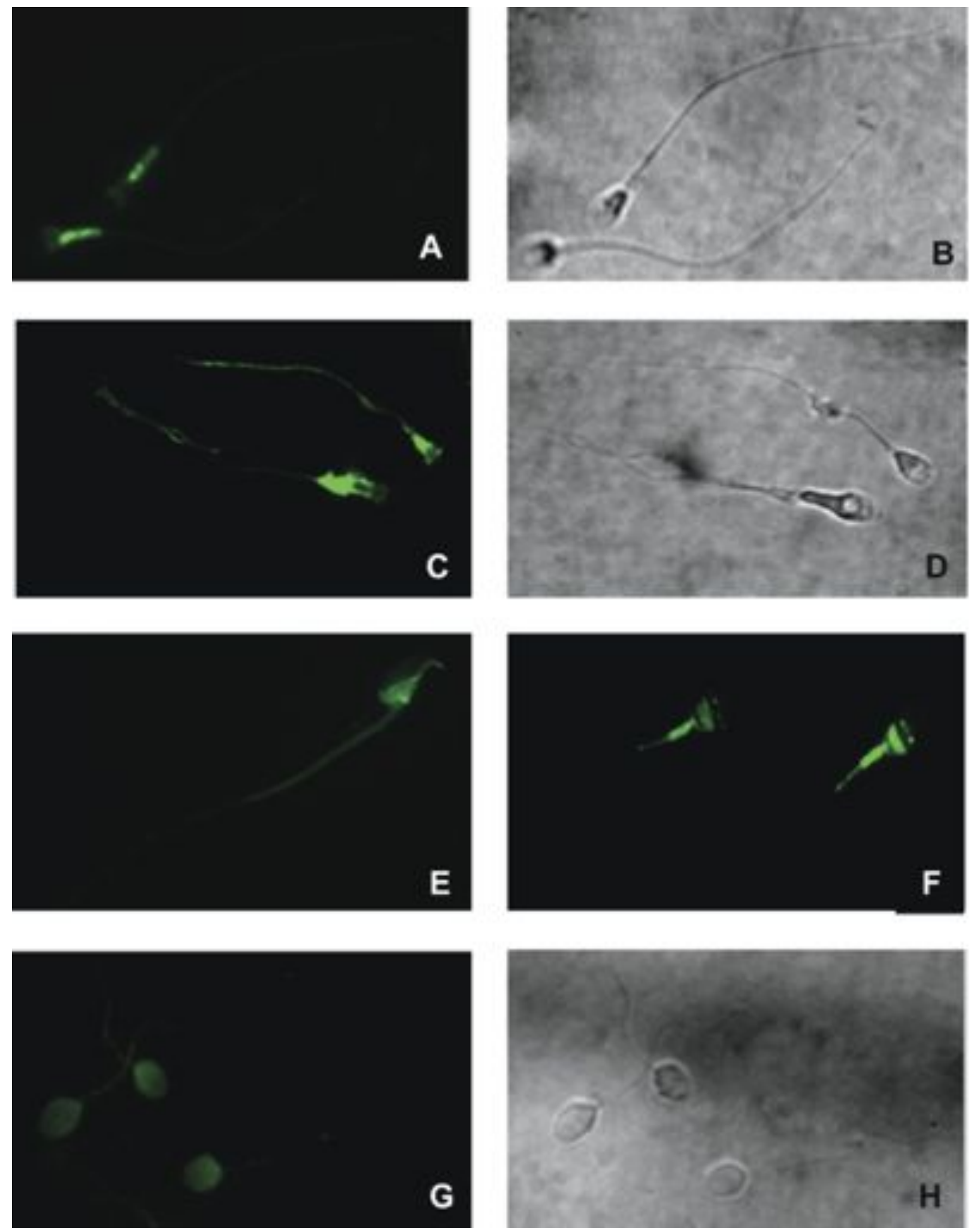

Fig.1:

UV micrographs of HN in human (A-D; G-H), mouse (E), and rabbit (F) spermatozoa after ICC. A, E, F) Normal human, mouse and rabbit sperm are labeled in the mid-piece and sub-acrosomal region. C) Altered human sperm are labeled in the flagellum also at acrosomal level. G) After swelling test, human spermatozoa are labeled in the heads. B, D, H) Phase contrasts. X 1,000 
(overnight at $4^{\circ} \mathrm{C}$ ) at its working dilution (1:50) with HN synthetic peptide (BACHEM AG, Bubendorf, Switzerland). After the incubation an ICC analysis was carried out in human ejaculated spermatozoa, as written above.

\section{Immunoelectronmicroscopy}

Human ejaculated spermatozoa and testis were embedded in Lowicryl K4M according to Carlemalm et al. (12). Ultrathin sections, mounted on gold grids, were saturated for $20 \mathrm{~min}$ with Tris-buffered saline (TBS)/1\% BSA containing 5\% NGS and treated overnight at $4^{\circ} \mathrm{C}$ with the rabbit polyclonal anti-HN antibody (Sigma-Aldrich) diluted 1:50 in TBS/0.1\% BSA/1\% NGS. For the detection, a goat anti- rabbit IgG antibody conjugated with colloidal gold and diluted 1:50 was used. After deep rinsing the grids were stained with uranyl acetate, then observed and photographed with the EM208 electron microscope (Philips Scientifics, Eindhoven, The Netherlands).

\section{Swelling}

In order to check the presence of HN at nuclear level, human spermatozoa were treated with $0.01 \mathrm{~mol} / \mathrm{l}$ dithiothreitol (Biorad, USA) in $0.1 \mathrm{~mol} / \mathrm{l} \mathrm{Tris} / \mathrm{HCl}(\mathrm{pH}$ 8), followed by $20 \mathrm{mmol} / \mathrm{l}$ 3,5-diiodosalicylic acid, lithium salt (Sigma-Aldrich) in the same buffer. When sperm heads were swelled, ICC procedure was performed.

\section{Western blotting}

Western blotting analyses were performed using fresh human semen samples.

The samples were mixed with RIPA lysis buffer and then sonicated. Total protein lysates were analyzed by SDS-PAGE and then transferred onto PVDF membrane, using a Novablot semidry transblot cell (BioRad). The blots were incubated with anti-HN polyclonal antibody (Sigma-Aldrich). The immunoreactive bands were visualized by horseradish peroxidase conjugated anti-rabbit (Sigma-Aldrich), followed by autoradiography.

\section{Results}

ICC analysis performed in human sperm samples using rabbit polyclonal anti-HN antibodies (SigmaAldrich and a self made antibody P04) showed the same localization for both antibodies. In particular, normal human sperm showed HN labeling in sub-acrosomal and mid-piece regions (Fig.1 A, B), whereas abnormally shaped sperm were stained also at acrosomal level and in the flagellum (Fig.1 C, D). Mouse and rabbit sperm were labeled as normal human sperm, even if rabbit sperm showed also two spots detected at acrosomal level (Fig.1 E, F). The controls were totally unstained.

The specificity of the rabbit polyclonal anti-HN antibody (Sigma-Aldrich) was verified by the preadsorption test using the $\mathrm{HN}$ synthetic peptide: if the antibody recognizes the peptide, both the antibody and
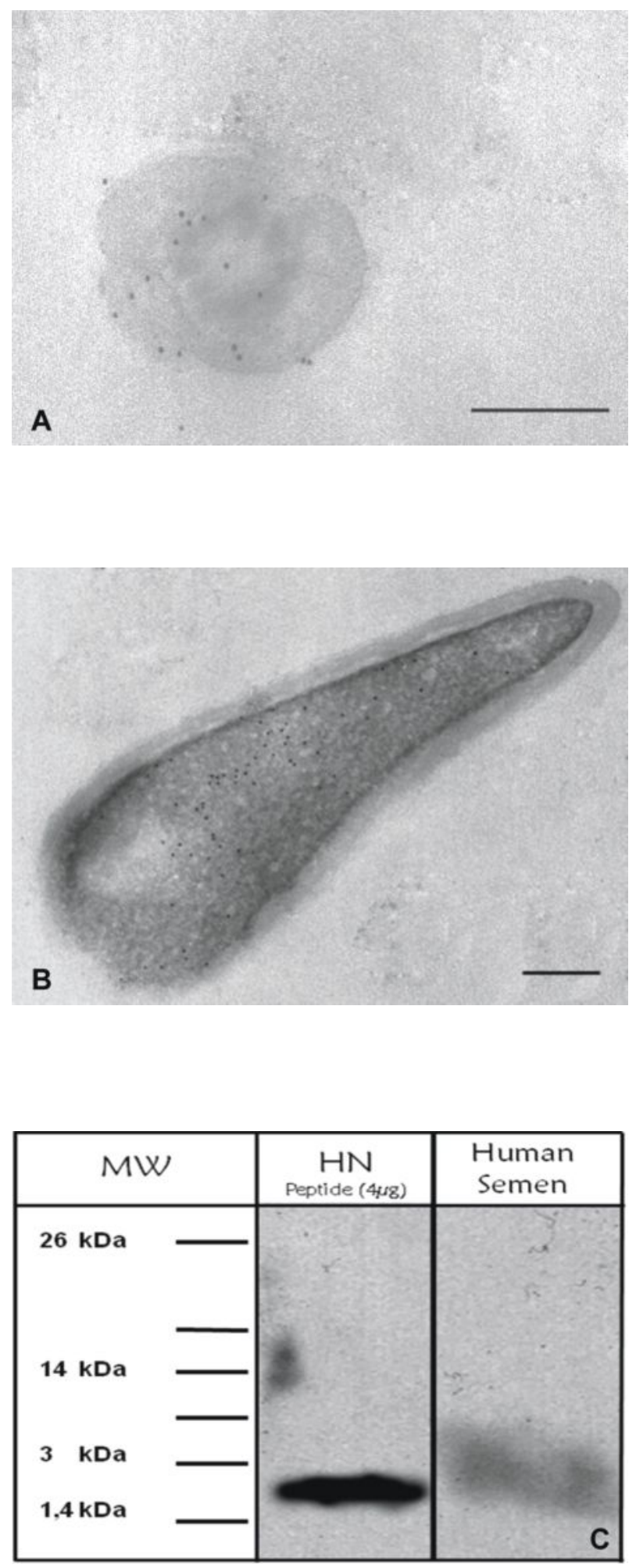

Fig.2:

A, B) TEM micrographs of cross and longitudinal sections of human spermatozoa after immunoeletronmicroscopy analysis. $\mathrm{HN}$ is present in the mitochondria $(\mathrm{A}, \mathrm{Bar} 0,2 \mu \mathrm{m})$ and also at chromatin level (B, Bar 0,4 $\mu \mathrm{m})$.

C) Western blotting of fresh pooled human semen samples; HN peptide is the positive control. 
the peptide will bind to each other, forming precipitating complexes. Any staining was observed in ICC performed in human sperm after incubation of antibody with HN synthetic peptide (data not showed).

The immunoeletronmicroscopy carried out in human sperm, confirmed the presence of HN in the mitochondria (Fig.2 A), but unexpectedly a strong labeling was observed also at chromatin level (Fig.2 B). In order to confirm the presence of $\mathrm{HN}$ in human sperm nucleus, an ICC analysis was repeated after that a swelling test was performed on ejaculated sperm. This procedure, able to uncoil the tightly packed sperm chromatin, allows the access of antibodies inside the nucleus. After swelling test sperm heads showed HN labeling even in ICC (Fig.1 G, H).

Western blotting analysis revealed the presence of $\mathrm{HN}$ in pooled human semen samples (Fig.2 C).

\section{ConClusion}

The vast majority of the studies concerning the male reproductive system and the presence of $\mathrm{HN}$ was performed in rat testicular tissue.

$\mathrm{HN}$ is demonstrated to be present at all stages of maturation in the rat testis and seems to promote the survival of Leydig cells in culture and to interact with IGF-I stimulating DNA synthesis and steroidogenesis (9). For these reasons anti-apoptotic properties of HN were postulated also at testicular level. Recently, Lue et al. (10) reported that IGFBP3, a proapoptotic factor, and $\mathrm{HN}$, a potent cell survival peptide, are important regulators of male germ apoptosis in rats, coordinating the regulation of testicular germ cell homeostasis, further validating the protective role of this peptide.

It has been reported that HN is also expressed in human testis (8) particularly in primary spermatocytes, suggesting a role in meiosis.

To the best of our knowledge this is the first time that HN was detected directly in human, rabbit and mouse spermatozoa.

The presence of HN in sperm of several animal species could suggest that $\mathrm{HN}$, an evolutionarily conserved protein, may play an important protective role in male reproductive system.

Our results demonstrated the presence of HN in human normally shaped sperm particularly in the mitochondria. This localization led us to hypothesize that HN may physiologically suppress mitochondrially-mediated apoptosis. On the contrary abnormal spermatozoa showed a different localization pattern displaying a diffuse fluorescence in the head and in the entire tail, leading to suppose that $\mathrm{HN}$ can attempt to envelope the whole spermatozoon in order to amplify its protective effect.

Immunoelectronmicroscopy and ICC performed after swelling test allowed to highlight HN even at chromatin level. The possible interaction between this protein and DNA should be a speculative explanation for this localization.

The mechanism of action of HN is still be unraveled; $\mathrm{HN}$ has been shown to interact with putative receptors
(10). Next step in this research should be to explore the possibility that human germ cells and spermatozoa could express some of these candidate receptors.

\section{REFERENCES}

1. Hashimoto Y, Niikura T, Ito Y, Sudo H, Hata M, Arakawa E, Abe Y, Kita Y, Nishimoto I. Detailed characterization of neuroprotection by a rescue factor humanin against various Alzheimer's disease-relevant insults. J Neurosci 2001; 21: 9235-9245

2. Guo B, Zhai D, Cabezas E, Welsh K, Nouraini S, Satterthwait AC, Reed JC. Humanin peptide suppresses apoptosis by interfering with Bax activation. Nature 2003; 423:456-461 3. Ikonen M, Liu B, Hashimoto Y, Ma L, Lee KW, Niikura T, Nishimoto I, Cohen P. Interaction between the Alzheimer's survival peptide humanin and insulin-like growth factorbinding protein 3 regulates cell survival and apoptosis. Proc Natl Acad Sci U S A 2003; 100:13042-13047

4. Ying G, Iribarren P, Zhou Y, Gong W, Zhang N, Yu ZX, Le Y, Cui Y, Wang JM. Humanin, a newly identified neuroprotective factor, uses the G protein-coupled formylpeptide receptor-like-1 as a functional receptor. J Immunol 2004; 172:7078-7085

5. Hashimoto Y, Suzuki H, Aiso S, Niikura T, Nishimoto I, Matsuoka M. Involvement of tyrosine kinases and STAT3 in Humanin-mediated neuroprotection. Life Sci 2005; 77:30923104

6. Hashimoto Y, Kurita M, Aiso S, Nishimoto I, Matsuoka M. Humanin inhibits neuronal cell death by interacting with a cytokine receptor complex or complexes involving CNTF receptor alpha/WSX-1/gp130. Mol Biol Cell 2009; 20:28642873

7. Caricasole A, Bruno V, Cappuccio I, Melchiorri D, Copani A, Nicoletti F. A novel rat gene encoding a Humanin-like peptide endowed with broad neuroprotective activity. FASEB J 2002; 16:1331-1333

8. Liang G, Zhang XD, Wang LJ, Sha YS, Zhang JC, Miao SY, Zong SD, Wang LF, Koide SS. Identification of differentially expressed genes of primary spermatocyte against round spermatid isolated from human testis using the laser capture microdissection technique. Cell Res 2004; 14:507-512

9. Colón E, Strand ML, Carlsson-Skwirut C, Wahlgren A, Svechnikov KV, Cohen P, Söder O. Anti-apoptotic factor humanin is expressed in the testis and prevents cell-death in Leydig cells during the first wave of spermatogenesis. J Cell Physiol 2006; 208:373-385

10. Lue Y, Swerdloff R, Liu Q, Mehta H, Sinha Hikim A, Lee KW, Jia Y, Hwang D, Cobb LJ, Cohen P, Wang C. Opposing Roles of Insulin-Like Growth Factor Binding Protein 3 and Humanin in the Regulation of Testicular Germ Cell Apoptosis. Endocrinology. 2009; Epub ahead of print

11. World Health Organization. WHO laboratory manual for the examination of human semen and semen-cervical mucus interaction. 4th ed. Cambridge, Cambridge University Press 1999

12. Carlemalm E, Villiger W, Hobot JA, Acetarin JD, Kellenberger E. Low temperature embedding with Lowicryl resins: two new formulations and some applications. J Microsc. 1985; 140: 55-63 